\title{
Evaluation of the PhP System for biochemical-fingerprint typing of strains of Salmonella of serotype Typhimurium
}

\author{
M. KATOULI, I. KÜHN*, R. WOLLIN* and R. MÖLLBY \\ Department of Bacteriology, Karolinska Institute, S-104 01 Stockholm and * The National Bacteriological Laboratory, \\ S-105 21 Stockholm, Sweden
}

\begin{abstract}
Summary. The Phene Plate (PhP) system of biochemical fingerprinting of bacteria is a computerised typing system, based on quantitative measurements of the kinetics of several biochemical reactions of bacteria grown in liquid medium in microtitration plates. For each isolate tested, it yields a biochemical fingerprint comprising several kinds of quantitative data which are useful for establishing similarities among strains with a personal-computer program. In this study, a set of 16 specific substrates was chosen to differentiate strains of Salmonella of serotype Typhimurium. The system was evaluated for its typability, reproducibility and discriminatory power in tests with a collection of 100 epidemiologically unrelated Typhimurium strains and results were compared with those obtained by phage typing. At an identity level of 0.980 , strains were assigned by this method to 51 biochemical phenotypes (BPTs), giving a diversity index of 0.963 and a resolution index of 0.210 . In contrast, 24 phage types (PTs) were identified among these isolates (a diversity index of 0.901). The combined use of biochemical fingerprinting by the PhP system and phage typing discriminated 82 phenotypes (a diversity index of 0.994 ). Stability of markers in each of the methods was also evaluated after subculture of 20 strains for 21 consecutive days. Only nine biochemical reactions were found that were subject to small, but measurable, changes for at least one isolate. These changes slightly decreased the mean similarity coefficients among strains but the overall BPTs of the strains showed changes in four strains $(20 \%)$. In contrast, eight strains $(40 \%)$ showed changes in their PTs after this treatment. It is concluded that the PhP system is a highly discriminatory and reproducible method for typing Typhimurium strains. It is easy to perform, and may be used alone or in combination with phage typing in epidemiological studies of Typhimurium strains.
\end{abstract}

\section{Introduction}

Of the various typing methods used in epidemiological studies of strains of Salmonella of serotype Typhimurium, the methods most widely used include biotyping, ${ }^{1,2}$ phage typing, ${ }^{3-5}$ antimicrobial-susceptibility testing ${ }^{6,7}$ and colicin typing. ${ }^{8}$ Recent advances in gene technology have provided additional new typing methods based on genotypic characterisation. These latter methods include multilocus-enzyme electrophoresis of allo-enzymes, ${ }^{9}$ plasmid-profile analysis, ${ }^{10-12}$ and restriction-endonuclease analysis of plasmid or chromosomal DNA. ${ }^{13,14}$ Relative advantages and disadvantages associated with these methods have been evaluated in comparative studies. ${ }^{15}$ To obtain further definition of epidemic strains, combinations of these methods have also been used. ${ }^{16-18}$ Despite the current enthusiasm for genotypic typing of bacteria, characterisation of Typhimurium strains still relies upon phage typing or biotyping used alone or together. ${ }^{19-21}$
The first scheme for biotyping Typhimurium strains, introduced by Kristensen et al., ${ }^{22}$ was based on the fermentation of nine substrates. More recently, that scheme was further developed by Duguid et al. ${ }^{2}$ who used a "two-stage" biotyping method comprising a primary typing step, in which their five most reliable and discriminatory tests were used, followed by a secondary step whereby "sub-types" of strains were distinguished on the basis of another 10 tests. Although that method provides excellent discrimination of Typhimurium strains, some consider it too laborious, particularly when many strains have to be tested.

$\mathrm{Küh}^{23}$ developed a computer-based typing method of biochemical fingerprinting (the Phene Plate system) that quantitatively measures the kinetics of several biochemical reactions of bacteria grown in liquid medium in microtitration plates. For each strain tested, the method yields a biochemical fingerprint, consisting of different kinds of quantitative data, which are used by means of numerical analysis to calculate similarities among tested strains with a specially designed personal-computer program for 
numerical analysis. In this study, a set of substrates specially selected for typing strains of Typhimurium was used to evaluate the system with regard to typability, reproducibility and discriminatory power and to compare its results with those from phage typing. An attempt was also made to measure the stability of typing characters of strains after repeated subculture.

\section{Materials and methods}

\section{Bacterial strains}

Two independent series of Typhimurium strains were examined. The first, comprising 100 epidemiologically unrelated strains isolated from 1988 to 1991 in 56 countries worldwide, was selected from the collection held at the National Bacteriological Laboratory (NBL), Stockholm, Sweden, on the basis of country of origin and year of isolation. To minimise epidemiological links among strains, care was taken to select strains isolated in different years if more than two strains were selected from any country (table I). Strains had been stored on deep agar at $4^{\circ} \mathrm{C}$ for $\leqslant 3$ years.

The second set, comprising 45 strains isolated from three outbreaks ( 15 strains each) of food-borne disease in Sweden from 1987 to 1991, was also obtained from the NBL collection and had been stored on deep agar at $4^{\circ} \mathrm{C}$ since isolation. The first outbreak occurred in April 1991 at a congress in Barbados attended by 180 Swedish businessmen among whom there were 72 known cases of infection caused by Typhimurium strains of phage-type 8 . The second outbreak in Oct. 1990 involved a restaurant in Vellinge in the south of Sweden with 118 guests infected by Typhimurium strains of phage-type 9 . The third outbreak occurred at a meeting of 2600 chorus singers in Skinskatteberg in central Sweden in July 1987 with 36 persons infected by Typhimurium strains of phage-type 9NST.

\section{Phage typing}

Strains were phage typed by the scheme of Lilleengen. ${ }^{24}$ Suspensions of bacteria, grown in nutrient broth for $16 \mathrm{~h}$ at $37^{\circ} \mathrm{C}$, were flooded on to the surface of plates of nutrient agar from which excess broth was then removed. Plates were dried for $10 \mathrm{~min}$ at $37^{\circ} \mathrm{C}$ in a ventilated incubator. Drops $(c .50 \mu \mathrm{l})$ of each of 12 typing phages (at routine-test dilution, RTD) were applied to the surface of agar plates and were incubated for $4 \mathrm{~h}$ at $37^{\circ} \mathrm{C}$. Isolates showing lytic patterns consistent with recognised phage types were so designated, whereas isolates with a discrete lytic pattern not consistent with that of any recognised phage type were designated as non-specific types (NST). The leading number, e.g., 9NST, indicates the number of phages not active on the tested strain. Depending on susceptibility to different phages, NST groups were divided into subgroups, indicated by a small letter. Strains not sensitive to any phages were referred to as nontypable (NT).

\section{Biochemical fingerprinting}

The principle of the PhP system and the preparation of plates have been described before, ${ }^{23,25}$ the 16 substrates selected for typing Typhimurium strains were D-mannoic-lactone, D-xylose, trehalose, melibiose, inosine, inositol, sorbitol, rhamnose, L-fucose, tagatose, $\beta$-methyl-glucoside, 5-ketogluconate, galactonic-lactone, citrate, pyruvate and $\mathrm{L}$-tartrate.

One colony of the test strain was picked from a purity plate on MacConkey agar and grown on nutrient agar at $37^{\circ} \mathrm{C}$ overnight. A loopful of this latter culture was suspended in $8 \mathrm{ml}$ of sterile Proteose Peptone (Difco) $0.1 \% \mathrm{w} / \mathrm{v}$ containing bromothymol blue $0.01 \% \mathrm{w} / \mathrm{v}$ and aliquots $(150 \mu \mathrm{l})$ were inoculated to 16 wells in pre-prepared microtitration plates containing each of the above 16 substrates at a concentration of $3.75 \mathrm{~g} / \mathrm{L}$. To allow proper rehydration of substrates, plates stored at $4^{\circ} \mathrm{C}$ overnight were incubated at $37^{\circ} \mathrm{C}$ the following morning. The absorbance $\left(A_{620}\right)$ of each reaction was measured at 4, 7, 24 and $48 \mathrm{~h}$ on a Microplate Reader (Titertek Multiscan, Flow Laboratories). The absorbance values, transferred automatically to a personal computer (VictorV286C), were multiplied by 10 , so yielding scores ranging from 0 to 30 for each reaction; low values indicated acidic (yellow) reactions and high values alkaline (deep-blue) reactions. After the final reading, the mean value of four readings was calculated providing 16 different numbers ranging from 0 to 30 for each strain (the biochemical fingerprint). Similarities between strains were calculated as correlation coefficients (r), as described before ${ }^{23}$ and clustered according to the unweighted-pair group method with arithmetic averages (UPGMA), ${ }^{26}$ so yielding a dendrogram. The handling of data, including optical readings, was performed with $\mathrm{PhP}$ software (BioSys, inova, Stockholm).

\section{Reproducibility and identity level}

Inter-assay reproducibility was calculated as the mean correlation coefficient (r) obtained from independent duplicate assays of 12 Typhimurium isolates and the identity level of the PhP system was set at that reproducibility -2 standard deviations (SD) (95\% confidence level). ${ }^{27}$ When compared strains had $r$ values greater than the identity level, they were assigned to the same biochemical phenotype (BPT). BPTs with $>1$ isolate were called common BPTs; those containing only one isolate were called single BPTs.

\section{Discriminatory power}

Three different methods of measuring discriminatory power were used. The resolution index was calculated as $1-$ mean of correlation coefficients $\left(\mathbf{r}_{\text {mean }}\right)$ 
Table I. Sources, phage types and biochemical phenotypes of 100 strains of Salmonella of serotype Typhimurium used in evaluation of PhP-system

\begin{tabular}{|c|c|c|c|c|}
\hline $\begin{array}{l}\text { Country } \\
\text { of } \\
\text { origin }\end{array}$ & $\begin{array}{c}\text { Year of } \\
\text { isolation } \\
\text { (number, if }>1 \text { ) }\end{array}$ & $\begin{array}{l}\text { Number } \\
\text { tested }\end{array}$ & $\begin{array}{c}\text { Phage type(s) } \\
\text { (Number, if }>1 \text { ) }\end{array}$ & $\begin{array}{c}\text { Biochemical } \\
\text { phenotype(S) } \\
\text { (number, if }>1 \text { ) }\end{array}$ \\
\hline Albania & 1989,90 & 2 & $1,4 \mathrm{NST}$ & $\mathrm{C} 5, \mathrm{~S} 14$ \\
\hline Angola & 1990 & 1 & 15 & S11 \\
\hline Australia & $1989(2), 91$ & 3 & 8,4 NST, 23 & $\mathrm{C} 1, \mathrm{C} 3, \mathrm{~S} 36$ \\
\hline Bangladesh & 1989 & 1 & 9NST & $\mathrm{C} 8$ \\
\hline Bolivia & 1990 & 1 & $11 \mathrm{NST}$ & $\mathrm{C} 10$ \\
\hline Brazil & 1989 & 1 & 11NST & S37 \\
\hline Bulgaria & 1989(2), 90 & 3 & $15,1(2)$ & $\mathrm{C} 2, \mathrm{~S} 20, \mathrm{~S} 32$ \\
\hline Canada & 1989 & 1 & $11 \mathrm{NST}$ & S19 \\
\hline China & 1989(3) & 3 & $11 \mathrm{NST}(2), 16$ & $\mathrm{C} 2, \mathrm{C} 8, \mathrm{~S} 39$ \\
\hline Cuba & 1989(2) & 2 & 5NST, 2 & $\mathrm{C} 3, \mathrm{~S} 15$ \\
\hline Cyprus & 1990 & 1 & $11 N S T$ & $\mathrm{Cl}$ \\
\hline Denmark & 1989(2), 90 & 3 & 28NST, 11NST, 10NST & $\mathrm{C} 1, \mathrm{C} 6, \mathrm{~S} 27$ \\
\hline Ecuador & $1989(2)$ & 2 & 2NST, 7NST & $\mathrm{C} 4, \mathrm{C} 8$ \\
\hline England & 1989,91 & 2 & 8,9 & $\mathrm{C} 3, \mathrm{C} 9$ \\
\hline Ethiopia & 1991 & 1 & 1 & $\mathrm{C} 4$ \\
\hline Finland & 1989 & 1 & 2 & S28 \\
\hline France & $1989(3), 90$ & 4 & NT, $16,3,8$ & $\mathrm{C} 8, \mathrm{Cl0}, \mathrm{S} 6, \mathrm{~S} 31$ \\
\hline Gambia & 1990 & 1 & $12 \mathrm{NST}$ & S12 \\
\hline Germany & 1989(2), 91 & 3 & 16, 11NST, 28NST & $\mathrm{C} 6(2), \mathrm{S} 1$ \\
\hline Greece & 1989(2), 90 & 3 & 21NSTa, 30NST, 5NST & C6, S9, S33 \\
\hline Holland & $1989(2), 90$ & 3 & 21, 21NSTa, 10NST & $\mathrm{C} 6(2), \mathrm{S} 17$ \\
\hline India & $1989(2)$ & 2 & NT, $11 \mathrm{NST}$ & S24, S40 \\
\hline Indonesia & $1989(2), 90$ & 3 & $11 \mathrm{NST}(3)$ & $\mathrm{Cl}(2), \mathrm{C} 8$ \\
\hline Iraq & 1991 & 1 & 8 & $\mathrm{C} 3$ \\
\hline Iran & $1989(2)$ & 2 & 9NST, NT & S16, S38 \\
\hline Italy & $1989(3), 90$ & 4 & 11NST(3), 28NST & $\mathrm{C} 6(2), \mathrm{C} 7, \mathrm{C} 8$ \\
\hline Jamaica & 1991 & 1 & 16 & $\mathrm{C} 2$ \\
\hline Japan & 1989 & 1 & 11 NST & C7 \\
\hline Kenya & 1989 & 1 & 21 & S41 \\
\hline S. Korea & 1989 & 1 & 2 & S34 \\
\hline Libya & 1989 & 1 & 28NST & C5 \\
\hline Lichtenstein & 1989 & 1 & 23 & S22 \\
\hline Malaysia & 1991 & 1 & NT & $\mathrm{C} 6$ \\
\hline Mexico & 1990 & 1 & 15 & S10 \\
\hline Nepal & 1989 & 1 & 6NST & $\mathrm{C} 12$ \\
\hline New Zealand & 1989,91 & 2 & 1, 2NST & $\mathrm{C} 5(2)$ \\
\hline Nigeria & 1990 & 1 & 1 & $\mathrm{C} 8$ \\
\hline Pakistan & 1990 & 1 & $11 \mathrm{NST}$ & C6 \\
\hline Poland & $1989(2)$ & 2 & $3(2)$ & S18, S25 \\
\hline Portugal & 1989,90 & 2 & $16,11 \mathrm{NST}$ & $\mathrm{S} 20, \mathrm{~S} 30$ \\
\hline Puerto Rico & 1990 & 1 & $28 \mathrm{NST}$ & S3 \\
\hline Singapore & 1989 & 1 & $11 \mathrm{NST}$ & S35 \\
\hline Somalia & 1989 & 1 & 8 & C3 \\
\hline Spain & 1989,90 & 2 & $22,11 \mathrm{NST}$ & $\mathrm{C} 5, \mathrm{~S} 7$ \\
\hline Sri Lanka & 1989,91 & 2 & $1,24 \mathrm{NST}$ & $\mathrm{C} 7, \mathrm{~s} 4$ \\
\hline Sweden & 1989(2), 90 & 3 & $1,3,15$ & $\mathrm{C} 8, \mathrm{~S} 8, \mathrm{~S} 29$ \\
\hline Switzerland & 1990 & 1 & NT & $\mathrm{C} 3$ \\
\hline Syria & $1989(2), 90$ & 3 & $11 \mathrm{NST}(2), 1$ & $\mathrm{C} 6, \mathrm{C} 7, \mathrm{~S} 23$ \\
\hline Tanzania & 1989 & 1 & 8 & $\mathrm{C} 3$ \\
\hline Thailand & $1989(2), 91$ & 3 & $16(2), 21$ & $\mathrm{C} 7, \mathrm{Cl} 2, \mathrm{Sl}$ \\
\hline Tunisia & $1989(3)$ & 3 & $11 \mathrm{NST}, 1,2 \mathrm{NST}$ & $\mathrm{C} 10, \mathrm{Cl1}(2)$ \\
\hline Turkey & 1989,90 & 2 & $16,11 \mathrm{NST}$ & $\mathrm{C} 1, \mathrm{~S} 26$ \\
\hline USA & 1990 & 1 & IINST & $\mathrm{Cl}$ \\
\hline Venezuela & 1991 & 1 & $11 \mathrm{NST}$ & $\mathrm{C} 4$ \\
\hline S. Vietnam & 1990 & 1 & 3 & S13 \\
\hline Yugoslavia & 1989,90 & 2 & 9,4 NST & $\mathrm{C} 9, \mathrm{C} 6$ \\
\hline Unknown & 1989 & 1 & 15 & $\mathrm{C} 2$ \\
\hline
\end{tabular}

obtained when all isolates within the studied population were compared. ${ }^{25}$ Variety was expressed as the number of phenotypes detected at the established identity level. Diversity was measured by Simpson's index of diversity (Di) ${ }^{27}$ according to the formula: $\mathrm{D}_{\mathrm{i}}=1-\Sigma[\mathrm{Ni}(\mathrm{Ni}-1)] /[\mathrm{N}(\mathrm{N}-1)]$, where $\mathrm{N}_{\mathrm{i}}$ is the number of isolates of the $i^{\text {th }}$ phenotype, and $\mathrm{N}$ is the total number of isolates tested. This index measures the probability that two randomly selected strains will be assigned to different phenotypes by the actual typing methods. ${ }^{27}$

\section{Phenotype stability}

Phenotype stability was studied with 20 isolates subcultured daily on Nutrient Agar (Difco) for 21 
Table II. Characteristics of 100 unrelated strains of Typhimurium by biochemical fingerprinting with the $\mathrm{PhP}$ system and phage typing

\begin{tabular}{lccc}
\hline Character & $\begin{array}{c}\text { Biochemical } \\
\text { fingerprinting }\end{array}$ & Phage typing & $\begin{array}{c}\text { Biochemical finger- } \\
\text { printing and } \\
\text { phage typing }\end{array}$ \\
\hline $\begin{array}{l}\text { Number of common types } \\
\text { (range of number of isolates) }\end{array}$ & $12(2-13)$ & $18(2-27)$ & $10(2-4)$ \\
$\begin{array}{l}\text { Number of single types } \\
\text { Typability }\end{array}$ & 39 & 6 & 72 \\
$\begin{array}{l}\text { Diversity index } \\
\text { Resolution index }\end{array}$ & $100 \%$ & $95 \%$ & $100 \%$ \\
Homogeneity & 0.963 & 0.901 & 0.994 \\
& 0.210 & NA & NA \\
\hline
\end{tabular}

NA: not applicable.

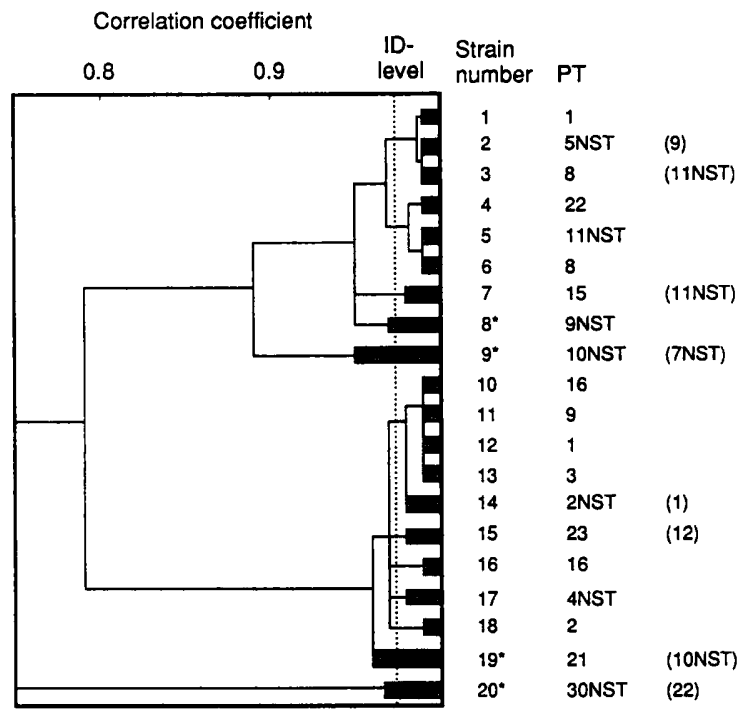

Fig. 1. Dendrogram showing similarities between biochemical phenotypes (BPTs) and phage types (PTs) of pairs of 20 Typhimurium strains before and after subculturing. Strains showing changes in BPTs are indicated (*) and changes in PTs are shown (in parentheses).

consecutive days. Changes in BPTs of isolates were measured in two ways. First, quantitative changes were measured for each biochemical reaction of strains before and after subculture. Change in any given test was calculated by measuring the inter-assay variation of that test obtained from duplicate assays of 12 Typhimurium strains. If a subcultured strain gave values outside the mean inter-assay variation $\pm 2 \mathrm{SD}$ for a test, when compared to the original culture of that strain, it was regarded as a change in that particular test. ${ }^{28}$ Second, the similarities obtained from comparisons of pairs of 20 strains before and after subculturing were calculated.

\section{Results}

\section{Inter-assay reproducibility and identity level}

The reproducibility of the PhP system was 0.991 (mean correlation of duplicate assays of 12 strains). It yielded an identity level of 0.980 , i.e., a mean correlation $-2 \mathrm{SD}(\mathrm{SD}=0.0057)$.
Table III. Mean values of changes (shown as numerical scores) in the biochemical reactions of 20 Typhimurium strains tested before and after subculturing*

\begin{tabular}{lccc}
\hline & \multirow{2}{*}{$\begin{array}{c}\text { Number of strains } \\
\text { Biochemical } \\
\text { reactions }\end{array}$} & \multicolumn{2}{c}{ Mean values of } \\
\cline { 3 - 4 } & showing changes & changes & SD \\
\hline D-Mannoic-lactone & 8 & -5 & $0 \cdot 7$ \\
Trehalose & 2 & -4 & - \\
Sorbitol & 6 & $-4 \cdot 7$ & $1 \cdot 1$ \\
Rhamnose & 6 & $-4 \cdot 2$ & $0 \cdot 4$ \\
Tagatose & 10 & $-4 \cdot 5$ & $0 \cdot 7$ \\
L-Fucose & 1 & -5 & - \\
$\beta$-Methyl-glucoside & 12 & $-4 \cdot 7$ & $0 \cdot 8$ \\
5-Ketogluconate & 2 & +4 & - \\
Galactonic-lactone & 3 & $-5 \cdot 3$ & $1 \cdot 2$ \\
\hline
\end{tabular}

SD, standard deviation.

* Subcultured for 21 consecutive days.

\section{Discriminatory power, variety and typability}

With biochemical fingerprinting, 100 unrelated Typhimurium strains were assigned to 12 common BPTs, each containing 2-13 isolates, and 39 single BPTs (table II); this gave a diversity index (Di) of 0.963 and a resolution of 0.210 with the $\mathrm{PhP}$ system. With phage typing, a total of 18 common phage types (PTs), each containing 2-27 isolates, and six single PTs were identified (Di of 0.901). Biochemical fingerprinting together with phage typing assigned strains to 10 common phenotypes, each containing 2-4 isolates, and to 72 single phenotypes; that gave a diversity index of 0.994 (table II). All strains were typable by the $\mathrm{PhP}$ system whereas five strains $(5 \%)$ could not be phage typed (table II).

\section{Phenotypic stability}

Changes in the fermentation rate of nine substrates were observed when subcultures of strains were compared with original cultures. The most frequent changes were seen with $\beta$-methyl-glucoside (12 strains), tagatose (10 strains) and D-mannoic-lactone (eight strains) (table III). Although these changes slightly affected the mean similarity coefficients between pairs of strains before and after subculturing, only four strains $(20 \%)$ showed changes in their BPTs. Yet, the similarity level of these strains and their non- 


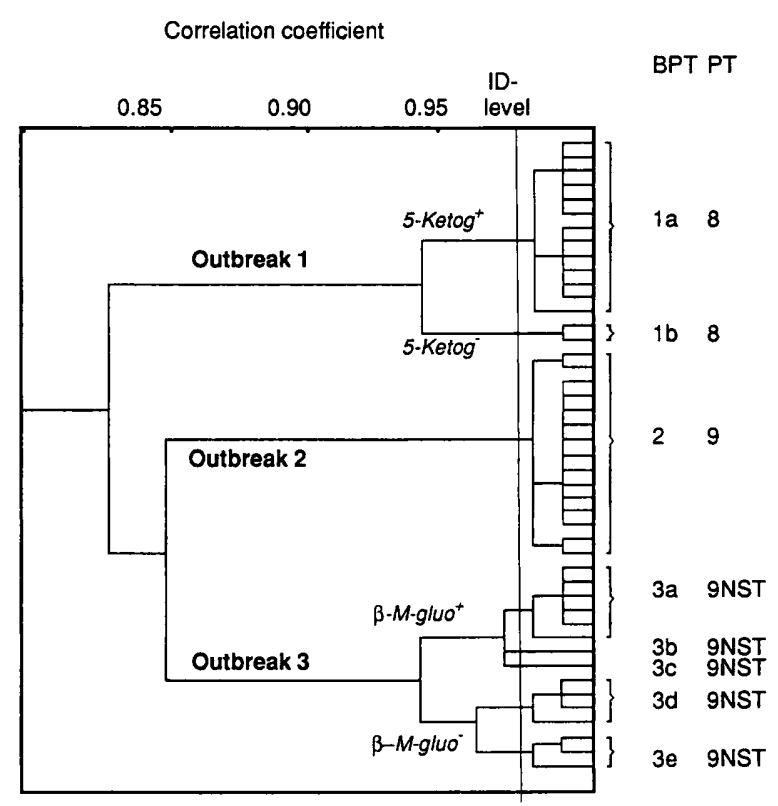

Fig. 2. Dendrogram showing biochemical phenotypes (BPTs) and phage types (PTs) of 45 Typhimurium strains from three foodpoisoning outbreaks.

subcultured duplicates was high (viz., 09960). In contrast, eight strains $(40 \%)$ showed changes in PTs after these procedures (fig. 1).

\section{Biochemical fingerprinting of outbreak strains}

Among 15 strains from outbreak 1, BPTs 1a (13 strains) and $1 \mathrm{~b}$ (2 strains) were represented (fig. 2); strains of these BPTs differ only in the rate of fermentation of 5-ketogluconate. The 15 strains from outbreak 2 belonged to BPT 2 . Among 15 strains from outbreak 2, three common BPTs-3a (six strains), 3d (four strains) and $3 \mathrm{e}$ (three strains)-and two single BPTs $-3 b$ and $3 c-$ were found (fig. 2). Strains of BPTs $3 d$ and 3e differ in the rate of fermentation of Dmannoic-lactone and 5-ketogluconate. Strains of BPT 3a, with a similarity level of 0.960 to these BPTs, differ from them mainly in their ability to utilise $\beta$-methylglucoside (fig. 2).

\section{Discussion}

The effective application of any typing method in epidemiological studies of bacteria depends on its ability to discriminate within species and to distinguish strains of different origins. An ideal method will also assign all tested strains to specific types and yield similar results for strains upon their repeated testing. Furthermore, the epidemiological markers should have sufficient genetic stability. It is also desirable that the method is easy to perform, especially for testing large numbers of strains. In the present study we evaluated these criteria for the PhP system. Reproducibility is the basis for other variables and determines the identity level of the system which ideally should be 1, i.e., duplicate assays performed on different occasions should give identical results. Here, reproducibility was calculated from inter-assay analy- sis of 12 duplicate samples and the identity level was set at the mean similarity between these duplicate assays -2 SD, giving a $95 \%$ confidence level which is desirable for a typing method. ${ }^{27}$

Simpson's diversity index measures the probability that two randomly selected isolates will be assigned to different groups and it is a measure of distribution of bacterial isolates to different types. ${ }^{27}$ Biochemical fingerprinting by the $\mathrm{PhP}$ system provided a high degree of discrimination among a collection of unrelated Typhimurium strains. The diversity index of the system when used alone was 0.963 , much higher than that postulated for confident interpretation of typing results. ${ }^{27}$ The corresponding value for phage typing was 0.901 . Discriminatory ability of a typing system is related to the number of types detected; in most cases, however, reproducibility of the system is inversely related to that ability. Thus, the discriminatory ability should, where possible, be measured at a reproducibility level of $\geqslant 95 \%$. However, it is often the case that the reproducibility of typing systems is either unknown or not reported ${ }^{27}$ In calculating the diversity index for phage typing, five non-typable (NT) strains were considered as one group. To allow for the possibility that these strains might have been typable by other phage-typing methods, the diversity index of phage typing was recalculated by assigning the five NT strains to five different presumed phage types. That recalculation improved the diversity index of phage typing only slightly to 0.903 (data not shown).

Biotyping has usually been used as a supplement to phage typing, ${ }^{29}$ colicin typing, ${ }^{16}$ plasmid-profile analysis $^{18}$ or other typing methods ${ }^{17}$ to provide further strain characterisation of Typhimurium. The combination of biochemical fingerprinting and phage typing used in this study proved to be highly discriminatory and gave a diversity index of 0.994 for a collection of epidemiologically unrelated Typhimurium strains. Similar results were also reported by Old and Barker ${ }^{30}$ who, evaluating the efficiency of biotyping alone or together with phage typing for an international collection of Typhimurium strains, obtained a diversity index of 0.984 for full biotyping used with phage typing. Our results support their findings and suggest that biochemical fingerprinting with phage typing is an ideal combination for epidemiological analysis of Typhimurium strains.

Kühn et al.$^{31,32}$ used the mean correlation coefficient $\left(\mathbf{r}_{\text {mean }}\right)$ among isolates to describe the homogeneity of a studied population. That coefficient measured the degree of relationship in a population and a low homogeneity indicated that strains were probably not related. Again, they showed that homogeneity in a population of "normal" strains of Escherichia coli was c. 0.63 , provided that the number of strains tested was high. ${ }^{23}$ However, among different groups of pathogenic strains of $E$. coli $^{31,32}$ or among strains of particular serotypes, ${ }^{31,33}$ this value was much higher because strains of a certain serotype are usually highly related. The PhP system gave a homogeneity of 0.790 
for a collection of unrelated strains of Typhimurium, a not unexpected finding because they belonged to one salmonella serotype.

The resolution index, which is also a specific variable of numerical typing methods, expresses the total discriminatory potentials of all substrates used in the $\mathrm{PhP}$ system. It was calculated as $1-r_{\text {mean }}$. If substrates yielding identical values for all isolates are included in the set, the resolution index will decrease. For example, in the present study, an initial test set with $\mathbf{4 8}$ different substrates was used to subtype Typhimurium strains; it gave a resolution of only 0.062 . However, with the removal of those tests giving identical results for a majority of isolates, the resolution index increased. Resolution index is a valuable tool for establishing an optimal set of tests for a particular group of bacteria. With biotyping, ideal tests are those which differentiate $50 \%$ of the strains within any given population. Nevertheless, tests giving less discrimination may also be included if they provide admissible quantitative or qualitative information about the organisms and if they are reproducible under the conditions established. The actual number of substrates used in this study was specifically selected from a large number of substrates to give a high degree of discrimination among Typhimurium strains.

Variety, i.e., the determination of the number of types obtained by any typing method, is also a measure of discriminatory power. The number of types (51) obtained with the PhP system was much higher than that obtained by phage typing (24), even when five NT strains were assigned to different, putative phage types. With conventional biotyping systems based on absolute "positive" or "negative" results, the theoretical variety is $2^{n}$, where $n$ is the number of tests. With a biochemical fingerprinting method in which quantitative values of each reaction may vary between 0 and 30 , the theoretical variety is $30^{\mathrm{n}}$, although not all possible biochemical fingerprints necessarily represent distinct types.

Stability of typing markers is another important factor in evaluating the efficiency of a typing method.

\section{References}

1. Barker RM, Old DC. Biotypes of Salmonella typhimurium of phage types 49, 204 and 193. J Med Microbiol 1980; 13: 369-371.

2. Duguid JP, Anderson ES, Alfredsson GA, Barker R, Old DC. A new biotyping scheme for Salmonella typhimurium and its phylogenetic significance. $J$ Med Microbiol 1975; 8: 149-166.

3. Anderson ES, Ward LR, de Saxe MJ, de Sa JDH. Bacteriophage-typing designations of Salmonella typhimurium. J Hyg 1977; 78: 297-300.

4. Guinée PAM, Jansen WH, van Schuylenberg A, van Leeuwen WJ. Bacteriophage typing of Salmonella typhimurium by use of a mechanized technique. Appl Microbiol 1973; 26: $474-477$.

5. Mitchell E, O'Mahoney M, Lynch D et al. Large outbreak of food poisoning caused by Salmonella typhimurium definitive type 49 in mayonnaise. $B M J 1989 ; 298$ : 99-101.

6. Anderson ES, Drug resistance in Salmonella typhimurium and its implications. BMJ 1968; 3: 333-339.
A reliable typing method should measure bacterial properties that are stable during the course of epidemic outbreaks. However, most strains are stored or subcultured before analysis. It is known that many bacterial properties change under these circumstances $;^{34,35}$ in contrast, biochemical phenotypes are little affected ${ }^{28}$ In this study, the four strains that showed changes in BPTs on subculture had a small drift in the rate of some biochemical reactions and yet their final similarity coefficients to other strains were quite high (see fig. 1). It is well known that bacteria with common ancestors eventually experience changes, ${ }^{36}$ although the extent of these changes cannot be predicted. Therefore, in epidemiological studies it is important not only to detect identical strains but also to investigate how similar non-identical isolates may be. With the PhP system, any variation in biochemical reactions encountered during bacterial spread would be easily recognised from the results and in the dendrogram, e.g., those observed among outbreak strains (see fig. 2). Again, in conventional biotyping small changes in biochemical reactions of bacteria cannot easily be detected unless a proper "positive" or "negative" change for a test is observed. Furthermore, the PhP system measures the kinetics of bacterial metabolism over $48 \mathrm{~h}$ and so presents a better picture of the biochemical activity of bacteria. The results may, of course, be different from those obtained by conventional biotyping. Whilst the stability of biochemical reactions of bacteria on non-selective media is of great importance in biotyping, non-fermenting strains may give rise to fermenting mutant strains on prolonged incubation in the substrate-containing medium. ${ }^{2}$ Within the incubation time used in the $\mathrm{PhP}$ system ( $48 \mathrm{~h})$, the chance of false-positive results due to emergence of mutant strains is very low, as has been shown by others. ${ }^{2}$

We thank Mrs Birgitta Karlsson for skilful technical assistance. This study was supported by The Swedish Board for Agricultural and Forestry Research (grants 0564/89 L 139 and 0777/89 D 326), The Swedish Farmers Foundation for Agricultural Research (grant 912912) and by The Karolinska Institute Fund.

7. Threlfall EJ, Ward LR, Rowe B. Epidemic spread of chloramphenicol-resistant strain of Salmonella typhimurium phage type 204 in bovine animals in Britain. Vet Rec 1978 103: $438-440$.

8. Barker RM. Colicinogeny in Salmonella typhimurium. J Gen Microbiol 1980; 120: 21-26.

9. Kapperud G, Lassen J, Dommarsnes $\mathrm{K}$ et al. Comparison of epidemiological marker methods for identification of Salmonella typhimurium isolates from an outbreak caused by contaminated chocolate. J Clin Microbiol 1989; 27: 2019-2024.

10. Olsvik Ø, Sørum H, Birkness $\mathrm{K}$ et al. Plasmid characterization of Salmonella typhimurium transmitted from animals to humans. J Clin Microbiol 1985; 22: 336-338.

11. Riley LW, di Ferdinando GT, de Melfi TM, Cohen ML. Evaluation of isolated cases of salmonellosis by plasmid profile analysis: introduction and transmission of bacterial clone by precooked roast beef. $J$ Infect Dis 1983; 148 12-17.

12. Taylor DN, Wachsmuth IK, Shankuan Y-H et al. Salmonellosis associated with marijuana. A multistate outbreak traced by 
plasmid fingerprinting. $N$ Engl $J$ Med 1982; 306: 1249-1253.

13. Platt DJ, Brown DJ, Old DC, Barker RM, Munro DS, Taylor J. Old and new techniques together resolve a problem of infection by Salmonella typhimurium. Epidemiol Infect 1987; 99: 137-142.

14. Brunner F, Margadant A, Peduzzi R, Piffaretti JC. The plasmid pattern as an epidemiological tool for Salmonella typhimurium epidemics: comparison with the lysotype. J Infect Dis 1983; 148: 7-11.

15. Holmberg SD, Wachsmuth IK, Hickman-Brenner FW, Cohen ML. Comparison of plasmid profile analysis, phage typing, and antimicrobial susceptibility testing in characterizing Salmonella typhimurium isolates from outbreaks. J Clin Microbiol 1984; 19: 100-104.

16. Barker R, Old DC. Biotyping and colicine typing of Salmonella typhimurium strains of phage type 141 isolated in Scotland. $J$ Med Microbiol 1979; 12: 265-276.

17. McDonough PL, Timoney JF, Jacobson RH, Khakhria R. Clonal groups of Salmonella typhimurium in New York State. J Clin Microbiol 1989; 27: 622-627.

18. Wray C, McLaren I, Parkinson NM, Beedell Y. Differentiation of Salmonella typhimurium DT204c by plasmid profile and biotyping. Vet Rec 1987; 121 : 514-516.

19. Barker RM, Old DC. The usefulness of biotyping in studying the epidemiology and phylogeny of salmonellae. $J$ Med Microbiol 1989; 29: 81-88.

20. Barker RM, Old DC, Sharp JCM. Phage type/biotype groups of Salmonella typhimurium in Scotland 1974-6: variation during spread of epidemic clones. $J$ Hyg 1980; 84: 115-125.

21. Lewis MJ, Stocker BAD. A biochemical subdivision of one phage type of Salmonella typhimurium. J Hyg 1971; 69: 683-691.

22. Kristensen M, Böjlen K, Faarup C. Bakteriologisk-epidemiologiske erfaringer om infektioner med gasteroenteritis baciller af paratyfusgruppen. Bibltk Laeger 1937; 129: 310-375.

23. Kühn I. Biochemical fingerprinting of Escherichia coli: a simple method for epidemiological investigations. $J$ Microbiol Methods 1985; 3: 159-170.

24. Lilleengen K. Typing of Salmonella typhimurium by means of bacteriophage. Acta Pathol Microbiol Scand 1948; Suppl. LXXVII.
25. Kühn I, Burman LG, Eriksson L, Möllby R. Subtyping of Klebsiella by biochemical fingerprinting: a simple system for epidemiological investigations. $J$ Microbiol Methods $1990 ; 11$ : 177-185.

26. Sneath PHA, Sokal R. Numerical taxonomy: the principles and practice of numerical classification. San Francisco, WH Freeman. 1973.

27. Hunter PR. Reproducibility and indices of discriminatory power of microbial typing methods. J Clin Microbiol 1990; 28: 1903-1905.

28. Katouli M, Kühn I, Möllby R. Evaluation of the stability of biochemical phenotypes of Escherichia coli upon subculturing and storage. J Gen Microbiol 1990; 136: $1681-1688$.

29. Anderson ES, Ward, LR, de Saxe MJ, Old DC, Barker R, Duguid JP. Correlation of phage type, biotype and source in strains of Salmonella typhimurium. J Hyg 1978; 81: 203-217.

30. Old DC, Barker RM. Numerical index of the discriminatory ability of biotyping for strains of Salmonella typhimurium and Salmonella paratyphi B. Epidemiol Infect 1989; 103: 435-443.

31. Kühn I, Franklin A, Söderlind O, Möllby R. Phenotypic variations among enterotoxigenic Escherichia coli from Swedish piglets with diarrhoea. Med Microbiol Immunol 1985; 174: 119-130.

32. Kühn I, Möllby R. Phenotyping variations among enterotoxigenic O-groups of Escherichia coli from various human populations. Med Microbiol Immunol 1986; 175: 15-26.

33. Katouli M, Kühn I, Möllby R. Biochemical phenotypes of enteropathogenic Escherichia coli common to Iran and Sweden. J Med Microbiol 1991; 35: 270-277.

34. Levine MM, Ristaino P, Sack RP, Kaper JB, Ørskov F, Ørskov I. Colonization factor antigens I and II and type 1 somatic pili in enterotoxigenic Escherichia coli: relation to enterotoxin type. Infect Immun 1983; 39: 889-897.

35. Evans DJ, Evans DG, DuPont HL, Ørskov F, Ørskov I. Pattern of loss of enterotoxigenicity by Escherichia coli isolated from adults with diarrhea: suggestive evidence for an interrelationship with serotype. Infect Immun 1977; 17: 105-111.

36. Ørskov F, Ørskov I. Summary of workshop on the clone concept in epidemiology, taxonomy and evolution of the Enterobacteriaceae and other bacteria. J Infect Dis 1983 148: $346-357$. 